\title{
A Retrospective Analysis of Drug Fever Diagnosed during Infectious Disease Consultation
}

\author{
Kenichiro Yaita, Yoshiro Sakai, Kenji Masunaga and Hiroshi Watanabe
}

\begin{abstract}
Objective To clarify the current situation concerning drug fever (DF) in Japan, we retrospectively analyzed patients undergoing infectious disease consultation at our institution.

Methods Between April 2014 and May 2015, we extracted the records of DF patients from among 388 patients who had obtained infectious disease consultations in Kurume University Hospital. We reviewed their medical charts and summarized the characteristics of DF.

Results This study included the records of 16 patients. Clinical signs (relative bradycardia, the duration of the drug administration before becoming febrile, and the interval between the discontinuation of a drug and the alleviation of a fever), and laboratory tests (varied white blood cell count, low level of C-reactive protein, and a mild elevation of transaminases) were compatible with those from previous reports. Among the drugconfirmed cases, five involved the use of glycopeptides (vancomycin: 3, teicoplanin: 2), which were considered to be uncommon causes, and the another five cases involved the use of $\beta$-lactams. In addition, the procalcitonin levels were either negative or low $(\leq 0.25 \mathrm{ng} / \mathrm{mL})$ in 10 of the 11 procalcitonin-measured cases.

Conclusion Our findings demonstrated that glycopeptides, similar to $\beta$-lactams, may be the origin of DF. Furthermore, procalcitonin may be helpful in the diagnosis of DF, but only in combination with other detailed examinations.
\end{abstract}

Key words: drug fever, glycopeptides, vancomycin, teicoplanin, procalcitonin

(Intern Med 55: 605-608, 2016)

(DOI: 10.2169/internalmedicine.55.5740)

\section{Introduction}

We occasionally encounter patients who are febrile, yet non-infectious, due to drugs. Although the mechanism of drug fever (DF) is unclear, the most common reason is thought to be the result of immune-mediated/hypersensitivity reactions (1). The typical characteristics of DF include an onset 7 to 10 days after drug administration, relative wellness, relative bradycardia, varied white blood cell (WBC) count (including neutropenia), elevation of eosinophils, and mildly elevated serum transaminases (1-4). Although these signs are well known, the diagnosis of DF remains challenging, because the correct diagnosis requires the exclusion of other non-localized febrile illnesses such as bacteremia. Eventually clinicians diagnose DF by a prompt improvement (within 3 days) after discontinuation of the suspected $\operatorname{drug}(\mathrm{s})(1)$.

Antibiotics are thought to be the most common offending drugs $(3,5)$, and $\beta$-lactams and trimethoprim/sulfamethoxazole are predominantly fever-causing antibiotics (2). A series of case reports concerning DF have been reported in the U.S., France, and Japan (6-11). In most of these reports, $\beta$ lactams are the common offending drugs, and the clinical characteristics of these DF cases were also compatible with previous review articles.

However, there has been very little new information concerning DF in Japan. The latest reports of a Japanese DF case series $(10,11)$ were published more than 20 years ago. We herein present an analysis of DF cases through the experience of infectious disease (ID) consultations in order to clarify the current tendencies of DF in Japan. 
Table 1. The Characteristics of Patients with Drug Fever.

\begin{tabular}{lc}
\hline & $(\mathrm{n}=16)$ \\
\hline $\begin{array}{l}\text { Age, mean } \pm \text { SD (year) } \\
\text { Sex (male) }\end{array}$ & $63.6 \pm 19.4$ \\
Past drug allergies a & 2 \\
Primary illnesses & 5 \\
$\quad$ Bacteremia (including IE) & 3 \\
$\quad \begin{array}{l}\text { Postoperative fever after TAR } \\
\text { (allergic reaction to vascular graft, suspected) }\end{array}$ & 2 \\
$\quad \begin{array}{l}\text { Pneumonia (HCAP and VAP) } \\
\text { Infective aortic aneurysm (suspected) }\end{array}$ & 2 \\
$\quad \begin{array}{l}\text { Surgical site infection (suspected) } \\
\quad \text { Postoperative intra-abdominal abscess }\end{array}$ & 1 \\
$\quad$ Febrile neutropenia & 1 \\
\hline $\begin{array}{l}\text { a: Includes a suspected case. b: Includes a patient that underwent } \\
\text { an operation for an open fracture of the lower leg and a patient that } \\
\text { underwent an operation for funnel chest. HCAP: health-care associated }\end{array}$ \\
$\begin{array}{l}\text { pneumonia, IE: infective endocarditis, SD: standard deviation, TAR: } \\
\text { total arch replacement, VAP: ventilator-associated pneumonia }\end{array}$
\end{tabular}

\section{Materials and Methods}

This research involved a single-center study that was conducted by the Department of Infection Control and Prevention, which manages ID consultations for every clinical department in Kurume University Hospital, a 1,025-bed tertiary care medical center. The Kurume University Research Ethics Committee (http://www.med.kurume-u.ac.jp/med/ joint/rinri/) approved this study (Research No. 14267). Between April 2014 and May 2015, 388 patients underwent ID consultation. We retrospectively reviewed their medical charts, and extracted the information of DF patients.

DF was defined by clinical characteristics that met all of the following criteria: 1 , an axial temperature above $37.5^{\circ} \mathrm{C}$ (in Japan, an oral or rectal temperature is generally not measured); 2, no other origin of fever can be detected by detailed ID consultation (including appropriate imaging tests and microbiological tests); 3, any underlying febrile illness, the improvement of which can be confirmed by the ID physician; and, 4, after the discontinuation of drugs, the fever is alleviated. These criteria were made in reference to previous studies (6-11) with some modification. We classified the following factors as patient-related: age, sex, primary illnesses, known allergies, antibiotics use, the duration of the drug administration before becoming febrile (days), clinical symptoms [the type of fever, the highest body temperature, eruption, and relative bradycardia (as defined by Cunha's report (2))], laboratory findings [peak WBC count, including neutropenia, and the levels of C-reactive protein (CRP), aspartate aminotransferase (AST), alanine aminotransferase (ALT) and procalcitonin (PCT)] during the febrile period, and the interval between the discontinuation of a drug and the alleviation of the fever (days).

\section{Results}

Among the 388 ID consulted cases, 16 patients met all
Table 2. The Clinical Characteristics of Patients with Drug Fever.

\begin{tabular}{|c|c|}
\hline & $(\mathrm{n}=16)$ \\
\hline \multicolumn{2}{|l|}{ Fever-causing drugs } \\
\hline Vancomycin & 3 \\
\hline Teicoplanin & 2 \\
\hline Piperacillin/Tazobactam & 2 \\
\hline Ampicillin/Sulbactam & 1 \\
\hline Cefazolin & 1 \\
\hline Ceftriaxone & 1 \\
\hline $\begin{array}{l}\text { Not clarified because two suspected drugs } \\
\text { were discontinued at the same time }\end{array}$ & 6 \\
\hline $\begin{array}{l}\text { The duration of the drug administration before becoming } \\
\text { febrile, mean } \pm \text { SD (days) }\end{array}$ & $8.6 \pm 5.3$ \\
\hline $\begin{array}{l}\text { The interval between the discontinuation of the drug and } \\
\text { alleviation of the fever, mean } \pm \mathrm{SD} \text { (days) }{ }^{\text {a }}\end{array}$ & $3.4 \pm 3.3$ \\
\hline \multicolumn{2}{|l|}{ The type of fever } \\
\hline A gradual increase & 10 \\
\hline Spike & 6 \\
\hline Eruption & 5 \\
\hline Relative bradycardia ${ }^{b}$ & 14 \\
\hline Highest $\mathrm{BT}$, mean $\pm \mathrm{SD}\left({ }^{\circ} \mathrm{C}\right)$ & $38.8 \pm 0.8$ \\
\hline
\end{tabular}

the qualifications for inclusion into this study. We could not determine the fever-causing agent in 6 cases because two drugs had been simultaneously discontinued. The profiles of the DF cases are summarized in Table 1 . The mean age \pm standard deviation (SD) was 63.6 \pm 19.4 years, and 10 patients were men. The primary illness of 5 of the patients was bacteremia with or without infective endocarditis. Two patients had allergies including one suspected case. One patient had a previous history of drug eruption due to cefoperazone/sulbactam, and another patient had a drug feversuspected history during the administration of meropenem and vancomycin. The clinical characteristics of patients with DF are described in Table 2. In the drug-confirmed cases, 5 patients had used glycopeptides (vancomycin: 3, and teicoplanin: 2), and the other 5 cases were caused by $\beta$-lactams (piperacillin/tazobactam: 2, ampicillin/sulbactam: 1, cefazolin: 1, and ceftriaxone: 1). The antibiotic therapies were discontinued in 6 cases, while the fever-causing drugs in 10 cases were discontinued and changed to other drugs. The mean duration of the drug administration before becoming febrile averaged $8.6 \pm 5.3$ days, and the mean interval between the discontinuation of the drug and the alleviation of the fever averaged 3.4 \pm 3.3 days. Clinical signs such as a gradually increasing fever, eruption and relative bradycardia were seen in 10,5 , and 14 patients, respectively, and the mean highest body temperature was $38.8 \pm 0.8^{\circ} \mathrm{C}$. The laboratory test results of patients with $\mathrm{DF}$ are presented in Table 3. The laboratory tests showed a peak WBC count of $7,519 \pm 3,551 / \mu \mathrm{L}$ (eosinophil count $429 \pm 575 / \mu \mathrm{L}$ ), a peak CRP level of $5.1 \pm 3.9 \mathrm{mg} / \mathrm{dL}$, a peak AST level of $47.7 \pm 46.0 \mathrm{IU} /$ L, a peak ALT level of 48.9 $\pm 59.5 \mathrm{IU} / \mathrm{L}$, and PCT was negative in 8 patients. During febrile periods, neutropenia and eosinophilia were detected in 4 and 4 patients, respectively. 
Table 3. Laboratory Tests of Patients with Drug Fever.

\begin{tabular}{lc}
\hline & $(\mathrm{n}=16)$ \\
\hline Peak WBC, mean $\pm \mathrm{SD}(/ \mu \mathrm{L})$ & $7,519 \pm 3,551$ \\
(Eosinophils, mean $\pm \mathrm{SD})(/ \mu \mathrm{L})$ & $(420 \pm 575)$ \\
Peak AST level, mean $\pm \mathrm{SD}(\mathrm{IU} / \mathrm{L})$ & $47.7 \pm 46.0$ \\
Peak ALT level, mean $\pm \mathrm{SD}(\mathrm{IU} / \mathrm{L})$ & $48.9 \pm 59.5$ \\
Peak CRP level, mean $\pm \mathrm{SD}(\mathrm{mg} / \mathrm{dL})$ & $5.1 \pm 3.9$ \\
Peak PCT level ${ }^{\mathrm{a}}$ & \\
$\quad \leq 0.1(\mathrm{ng} / \mathrm{dL})$ & 8 \\
0.1 - 0.25 $(\mathrm{ng} / \mathrm{dL})$ & 2 \\
$\quad>0.25(\mathrm{ng} / \mathrm{dL})$ & 4 \\
Neutropenia & 4 \\
Eosinophilia & 4 \\
\hline a: Not available in five patients. AST: aspartate aminotransferase, \\
ALT: alanine aminotransferase, CRP: C-reactive protein, PCT: \\
procalcitonin, SD: standard deviation, WBC: white blood cell
\end{tabular}

None of the patients exhibited serious drug-reactions.

\section{Discussion}

In this report, characteristics such as the duration of drug administration before becoming febrile, the time until improvement after the discontinuation of the drugs, relative bradycardia, a moderate to slightly elevated WBC count, a low level of CRP, and a mild elevation of transaminases were compatible with the results shown in previous reports. However, the prevalence of relative bradycardia and glycopeptides use was much higher than we expected. Furthermore, the PCT levels in most patients were either negative or low. All of our participants were seen for ID consultation, and relative bradycardia is an important clinical clue for ID physicians (5), which could have resulted in a bias in the triggers for suspecting DF.

Although glycopeptides, including vancomycin and teicoplanin, are considered to be rare DF-causing agents (12), previous cases have been described in the literature $(9,13-15)$. In a French national cohort study, which is the most recent report concerning DF, there were $5 \mathrm{DF}$ cases caused by glycopeptides from among 167 DF patients (9). Hung et al. described 117 cases where the medication was switched from vancomycin to teicoplanin due to $\mathrm{DF}$, rash or neutropenia during the treatment period (13). Their study reported 24 cases of DF alone and 8 cases of DF and rash (13). Other reports have included DF due to teicoplanin; one study reported 5/18 cases with rash during the treatment of bone, joint, and vascular-access-associated infections (14); and another study described 5/20 cases that included 3 with rash during the treatment of streptococcal endocarditis (15). In the modern era, with its prevalence of multi-drug resistant bacteria, glycopeptides have become important and frequently used drugs. The ratio of methicillinresistant Staphylococcus aureus / methicillin-susceptible Staphylococcus aureus sampled from clinical specimens in our hospital in 2014 was 1.07 (1,334/1,243 samples) (unpublished data), which may have been associated with the frequent use of glycopeptides, and there was a high preva- lence of glycopeptides as the causative agents of DF in the present study. Although the characteristics of glycopeptideinduced DF patients were similar to those of the patients affected by other drugs, one patient had a persistent fever for 12 days after the discontinuation of the teicoplanin. Piperacillin/tazobactam was administered at the surgeon's direction, and except for a fever, no trace of infection was detected by the ID physician. After a confirmation of significant eosinophilia $(2,173 / \mu \mathrm{L})$, a negative blood culture, and computed tomography showing negative results, piperacillin/ tazobactam administration was discontinued after 4 days. A serum concentration of teicoplanin that remained $(9.3 \mu \mathrm{g} /$ $\mathrm{mL}$ ) for 7 days after the discontinuation may have been the cause of the sustained fever.

Among most (91\%, 10/11 cases) of our study subjects, the PCT levels were either negative or low. PCT is a prohormone of calcitonin and is known to be generated during bacterial infections (16). However, PCT false-positive cases have also been reported in cases of major surgery, graftversus-host disease, and autoimmune disorders. A definitive report regarding the relationship between PCT and DF has not yet been reported in the pertinent literature. Delèvaux et al. analyzed the PCT levels in a bacterial/fungal infection group and an abacterial inflammatory group (17). In their study, the PCT levels of only 2 DF patients were available, and both were negative $(0.1 \mathrm{ng} / \mathrm{mL})(17)$. As mentioned above, the most critical and difficult differential diagnosis of DF is bacteremia without a clear focus. Schuetz et al. suggested a cut-off level of $0.25 \mathrm{ng} / \mathrm{mL}$ for excluding bacteremia (18). However, we do not always recommend that doctors measure the PCT level due to the inherent limitations of biomarkers. Following a detailed physical examination after the correct microbiological tests have been performed to diagnose febrile patients, PCT may then be helpful in diagnosing DF.

There are several limitations associated with this study. First, because we performed a retrospective study, some clinical findings may have been missed, although all cases were confirmed by ID physicians. To resolve these problems, we will continue to accumulate the data of our patients for a follow-up prospective analysis. Second, because our hospital is a tertiary care medical center, which admits critical patients from other hospitals, two or more antibiotics are often simultaneously administered in each patient. We were unable to clarify the causal drug for the $6 \mathrm{DF}$ patients. Third, other antibiotics were administered to most of our patients (10/16 cases) after the previous drugs had been stopped. This was because we could not discontinue antibiotics for primary infectious illnesses and could not rule out the possibility that other new nosocomial infections had occurred.

In conclusion, among 388 cases, 16 participants (4.1\%) were diagnosed with DF during ID consultation. Their clinical characteristics were similar to those of previous reports. Clinicians must consider the possibility that glycopeptides, similar to $\beta$-lactams, may be the causative agents of DF. Ad- 
ditionally, a negative or low procalcitonin level may be suggestive of DF.

The authors state that they have no Conflict of Interest (COI).

\section{Acknowledgement}

The authors thank all staff members of our hospital for their vigorous contribution to our practice.

\section{References}

1. Johnson DH, Cunha BA. Drug fever. Infect Dis Clin North Am 10: 85-91, 1996.

2. Cunha BA. Clinical approach to fever in the neurosurgical intensive care unit: focus on drug fever. Surg Neurol Int 4 (Suppl 5): S318-S322, 2013.

3. Patel RA, Gallagher JC. Drug fever. Pharmacotherapy 30: 57-69, 2010.

4. Tabor PA. Drug-induced fever. Drug Intell Clin Pharm 20: 413420, 1986.

5. Cunha BA. Fever of unknown origin: clinical overview of classic and current concepts. Infect Dis Clin North Am 21: 867-915, 2007.

6. Young EJ, Fainstein V, Musher DM. Drug-induced fever: cases seen in the evaluation of unexplained fever in a general hospital population. Rev Infect Dis 4: 69-77, 1982.

7. Mackowiak PA, LeMaistre CF. Drug fever: a critical appraisal of conventional concepts. An analysis of 51 episodes in two Dallas hospitals and 97 episodes reported in the English literature. Ann Intern Med 106: 728-733, 1987.

8. Pleasants RA, Walker TR, Samuelson WM. Allergic reactions to parenteral beta-lactam antibiotics in patients with cystic fibrosis.
Chest 106: 1124-1128, 1994.

9. Vodovar D, LeBeller C, Mégarbane B, Lillo-Le-Louet A, Hanslik T. Drug fever: a descriptive cohort study from the French national pharmacovigilance database. Drug Saf 35: 759-767, 2012.

10. Oizumi K, Onuma K, Watanabe A, Motomiya M. Clinical study of drug fever induced by parenteral administration of antibiotics. Tohoku J Exp Med 159: 45-56, 1989.

11. Mikasa K, Sawaki M, Konishi M, Kunimatsu M, Fujimura M, Narita N. Fever induced by antibacterial drugs. Nihon Kagakuryoho Gakkai Zasshi (Japanese Journal of Chemotherapy) 38: 2125, 1990 (in Japanese, Abstract in English).

12. Thong BY. Update on the management of antibiotic allergy. Allergy Asthma Immunol Res 2: 77-86, 2010.

13. Hung YP, Lee NY, Chang CM, Lee HC, Wu CJ, Chen PL. Tolerability of teicoplanin in 117 hospitalized adults with previous vancomycin-induced fever, rash, or neutropenia. Clin Ther 31: 1977-1986, 2009.

14. Greenberg RN. Treatment of bone, joint, and vascular-accessassociated gram-positive bacterial infections with teicoplanin. Antimicrob Agents Chemother 34: 2392-2397, 1990.

15. Venditti M, Gelfusa V, Serra $P$, Brandimarte $C$, Micozzi A, Martino P. 4-Week treatment of streptococcal native valve endocarditis with high-dose teicoplanin. Antimicrob Agents Chemother 36: 723-726, 1992.

16. Levy MM. Preface biomarkers in critical illness. Crit Care Clin 27: xiii-xv, 2011.

17. Delèvaux I, André $M$, Colombier $M$, et al. Can procalcitonin measurement help in differentiating between bacterial infection and other kinds of inflammatory processes? Ann Rheum Dis 62: 337-340, 2003.

18. Schuetz P, Albrich W, Mueller B. Procalcitonin for diagnosis of infection and guide to antibiotic decisions: past, present and future. BMC Med 9: 107, 2011.

(C) 2016 The Japanese Society of Internal Medicine http://www.naika.or.jp/imonline/index.html 